\title{
Os Objetos da Música e da Matemática e a Subalternação das Ciências em Alguns Tratados DE Música do SÉculo XVI
}

\author{
Carla Bromberg ${ }^{1}$
}

\begin{abstract}
RESUMO: Sabe-se que, durante alguns períodos da história, a Música e a Matemática foram ciências que compartilharam seus conceitos e discussóes. Um dos períodos no qual essa comunhão se deu de maneira significativa foi o Renascimento. A Música era entâo classificada como ciência e, pertencendo ao grupo das matemáticas, dividia seu espaço com a Aritmética, a quem era subordinada, com a Geometria e a Astronomia. Essa divisão foi transmitida através das obras do filósofo Sevério N. Boécio e prevaleceu durante o século XVI, juntamente da noção de subalternação das ciências, provida na obra de Aristóteles e de seus comentaristas. Contudo, durante a segunda metade do século XVI, o cenário teórico foi sofrendo questionamentos e sendo por vezes reformulado. Tais reformulaçóes tomaram várias formas, todavia, foi no diálogo entre dois autores específicos, Gioseffo Zarlino (1517-1590) e Vincenzo Galilei (1533?-1591), que a estrutura vigente foi realmente abalada. Neste artigo, pretendese mostrar a relevância da subalternação das ciências na discussão metodológica para a pretendida reformulaçáo teórica, visto que um dos problemas metodológicos centrais da demonstração nas ciências matemáticas do século XVI foi a reconciliação entre as condiçôes ideais, que governavam o mundo matemático, no caso específico o da Aritmética, e as condiçóes reais do mundo físico natural.
\end{abstract}

PALAVRAS-CHAVE: História da Ciência. Subalternação das Ciências. Classificação do Conhecimento. Música e Matemática. Renascimento.

\section{INTRODUÇÃo}

Sabe-se que, durante alguns períodos da história, a Música e a Matemática foram ciências que compartilharam seus conteúdos, sendo o Renascimento um dos períodos no qual essa comunhão se deu, de maneira significativa.

A Música, nesse período, era considerada uma ciência e pertencia ao grupo das matemáticas, assim como a Aritmética, a Geometria e a Astronomia. Essas ciências formavam o Quadrivium, termo sabidamente utilizado pelo

\footnotetext{
${ }^{1}$ Pós-Doutoranda no Centro Simão Mathias de Estudos em História da Ciência (CESIMA-PUC/SP). E-mail: cbromberg@pucsp.br. Agradecimentos à FAPESP pela Bolsa de Pós-Doutorado concedida, que viabilizou este trabalho.
} 
filósofo Sevério N. Boécio (ca.480-525), tido como uma derivação do termo quatro caminhos, anteriormente usado por Nicômaco de Gerasa (2a metade do séc. I) (BOWER, 1989). A relação entre Boécio e Nicômaco não se deu somente no empréstimo do termo, mas na compilação que Boécio fez das obras deste último (Manual de Harmonia e Introdução à Aritmética) e também da obra Harmonia, de Ptolomeu (BOWER, 1978). Essas obras foram sintetizadas em seu Institutione arithmetica, o primeiro de uma série de livros que caracterizaram as ciências do quadrivium.

\section{A ClassificaÇão da música e Boécio}

Em sua obra, Boécio subdividiu as ciências matemáticas em quatro, definindo os seus conhecimentos em termos de seus sujeitos, ou seja, quais fossem as suas essências, que se dividiam em dois tipos: a contínua e a discreta (MASI, 1983, p.71-72). Ele, de acordo com os preceitos de Nicômaco, identificou as duas primeiras ciências relacionadas ao número: de forma absoluta (Aritmética) ou relativa (Música), enquanto as duas outras tratavam da magnitude: de forma estável (Geometria) ou móvel (Astronomia) (MASI, 1983, p.71-72).

A definição da música como ciência matemática apareceu no tratado de aritmética (Istitutione, proemium; Arithmetica, XXX). Nele, Boécio explicou que a forma de apreensão dessa ciência se dava através do intelecto, pois não seria suficiente aos músicos deleitar-se com as cançóes, se não aprendessem como os sons estavam internamente estruturados pela proporção (CASTANHEIRA, 2009, p.64) ${ }^{2}$. Tanto o tratado sobre aritmética como o sobre a música debruçaram-se sobre a natureza matemática da última, sendo que, no primeiro, foram apresentadas as definições dos seus elementos, como números, suas espécies, razôes e proporçôes, enquanto, no segundo, suas finalidades morais, sua narrativa histórica e as relaçóes com os conceitos de som, intervalo, consonâncias, dissonâncias, modos e gêneros.

\footnotetext{
${ }^{2}$ Utilizo aqui a tradução para o português do livro I, da obra De istitutione musica, de Boécio, de acordo com a versão apresentada na dissertação de mestrado de Carolina Castanheira, cujas referências completas se encontram na bibliografia final.
} 


\section{2a A transmissão da ObRa de BoÉCio E A SUbalternaÇÃo da Música}

As obras de Boécio tiveram grande influência nos tratados de música da Renascença. As definiçóes providas por ele, em seu tratado de aritmética, prevaleceram durante o século $\mathrm{XVI}^{3}$, tanto nas obras teóricas de músicos, quanto na de matemáticos. Nicolò Tartaglia (ca.1500-1557) a utilizou em sua versão dos Elementos de Euclides (TARTAGLIA, 1577, A4v) e em seu tratado sobre números e medidas (TARTAGLIA, 1556, A); Egnazio Dante (15361586), em seu tratado sobre ciência matemática (DANTE, 1577, p.2-5), e, como se sabe, vários autores incluíram em suas obras sumários do tratado sobre aritmética, sabidamente desde o século XIII, como Luca Pacioli, principalmente na traduçâo italiana de 1523 do seu Summa de Arithmetica, além de Faber Stapulensis, Georgio Valla, Robert Record, entre outros (MASI, 2006, p.49-57).

O tratado de aritmética de Boécio não só baseou-se nas obras de Nicômaco de Gerasa e Ptolomeu, mas também incorporou trechos dos Elementos de Euclides, do Sectio canonis. Embora se mantivesse ancorado num contexto geral pitagórico, abrangeu também autores como Aristoxeno de Tarento (354-300 a.C.), cuja teoria, paradoxalmente, se opunha à dos pitagóricos (BOWER, 1978; CASTANHEIRA, 2009, p.30-38).

Conforme Boécio, a Música era uma ciência cujo objeto era de ordem numérica, um objeto de natureza quantitativa ${ }^{4}$. Para ele, os números se demonstravam anteriores, na Música, não só por serem os primeiros na natureza, mas por estarem antes daquilo que só poderia existir por relação (MASI, 1983, p.74) ${ }^{5}$ e, assim, os intervalos musicais eram definidos por relaçóes de razóes de números inteiros, mais especificamente razóes construídas com os íntegros de 1 a 4, como previa a doutrina pitagórica harmônica.

As ciências matemáticas constituíram-se ainda, para Boécio, num instrumento de alcance da filosofia, designadas como um grupo de disciplinas de caráter propedêutico (MASI, 1983, p.71) e deveriam estar livres das observaçôes

\footnotetext{
${ }^{3}$ A outra tradição presente no Renascimento é aquela transmitida através do livro nono do De nuptiis Philologiae et Mercurii, de Martianus Capella. Istitutione, de Boécio, e De nuptiis, de Capella, são as principais obras a trazerem o conhecimento sobre a música na antiguidade clássica; todavia, diferem em muitos aspectos, seja de linguagem, seja de amplitude, estilo, grau de detalhamento e fontes. Ver TEEUWEN (2002, p.162).

${ }^{4}$ A definição ou definições sobre o objeto da música não aparecerão novamente no livro Istitutione musica.

${ }^{5}$ Platão caracteriza os intervalos musicais por relaçôes de razóes de números inteiros, na República (531a1-2).
} 
físicas e de um comprometimento com a percepção sensorial. Na obra Istitutione musica, elementos de caráter moral e éticos foram incorporados (MASI, 1983, p.73-4, como fica claro em seu proêmio (CASTANHEIRA, 2009, p.49).

Essas obras de Boécio foram normalmente interpretadas por autores medievais como tentativas de conciliação entre as filosofias platônica e aristotélica. Autores como Johannes de Muris $^{6}$ (ca.1290-ca.1351) ou Robert Grosseteste (1175-1253), assim como outros comentaristas da obra de Aristóteles, corroboram essa tendência (RICO, 2005). Como se sabe, Boécio adotou uma postura aristotélica com relação às matemáticas a partir dos seus comentários sobre a Introdução de Porfírio (Isagoge), quando as matemáticas passaram a ter, não mais um caráter instrumental, mas uma posição própria dentro do sistema de Aristóteles (SCHRADE, 1947, p.195).

No sistema de Aristóteles, a Música era designada entre as chamadas ciências matemáticas, como a Ótica e a Astronomia, sendo que a Música era considerada, dentre elas, uma das mais naturais (Física, 194 a7). Para o filósofo, o número consistia igualmente no objeto da música. $\mathrm{O}$ número, atributo essencial do sujeito desta ciência, possuía uma parte imprópria, isto é, que derivava do acréscimo de uma diferença acidental ao gênero sujeito da música. Essa diferença acidental, ou qualidade, era o sonoro (Metafísica, 987b27). Boécio, diferentemente de Aristóteles, não fez menção, nos tratados sobre aritmética e música, ao objeto "número sonoro".

Assume-se que a intensificação da leitura do objeto musical como número sonoro tenha se dado através da obra de Roberto Grosseteste (c.1168-1253), considerado um dos primeiros latinos a comentar os Segundos Analíticos e a Física de Aristóteles (McEVOY, 1983 apud NASCIMENTO, 2009, p.202)7. Para ele, os sujeitos das disciplinas que Aristóteles apontou como as mais naturais das matemáticas ${ }^{8}$ eram compostos do matemático e do natural" (NASCIMENTO, 2009, p.204).

\footnotetext{
${ }^{6}$ Johannes de Muris é um autor cujos escritos englobam o estudo dos conhecimentos da astronomia, da astrologia, além da aritmética e da música. Para as áreas, que não música, ver THORNDIKE (1934, p.294-324).

7 Nesse artigo, o prof. Carlos A. Nascimento provê uma tradução do livro I, capítulo 12 do Comentário sobre os livros dos Analíticos Posteriores do latim, que é por mim adotada nas citaçóes. GROSSETESTE, R. Commentarius in posteriorum Analyticorum libros. Introduzione e texto critico di P. Rossi. Firenze: Leo S. Olski, 1981.

${ }^{8}$ Vale lembrar que Grosseteste usou a traduçáo da Física de Tiago de Veneza, que traduziu a expressão aristotélica "[...] as mais naturais entre as matemáticas" (Física, II, 2, 194a7) por "[...] mais física do que matemáticas".
} 
Como se sabe, as ciências, às quais pertenciam esses objetos, receberam a designação de subalternante (superior) e subalternada (inferior) (NASCIMENTO, 2009, p.211), e Grosseteste desenvolveu amplamente esse conceito, nos seus comentários sobre a Física de Aristóteles (MENDOZA, 2004). Thomas de Aquino (1225-1274), que também utilizou na música o termo "número sonoro", passou a atribuir a expressão ciências intermediárias às disciplinas que Aristóteles chamou de "[...] as mais naturais entre as matemáticas” (NASCIMENTO, 2007, p.56).

Aquino, no Comentário ao Tratado da Trindade de Boécio, principalmente na questáo cinco, ao classificar os tipos de artes liberais de acordo com suas relações, chamou a atenção à classificação das ciências subalternas. Segundo ele, uma ciência estaria compreendida sob outra como parte desta e isso poderia se dar de duas maneiras: a primeira, quando o seu sujeito fosse uma parte do sujeito da outra; a segunda, quando uma ciência superior determinasse o porquê daquilo de que, na ciência inferior, só se conheceria o quê (AQUINO, 1998, p.107), referindo-se à sua leitura de Grosseteste (AQUINO, 1998, p.24).

Grosseteste salientou, no seu capítulo 12 dos Comentários sobre os Analíticos Posteriores, que a ciência do porquê (subalternante) se diferenciava da ciência do quê (subalternada), por serem adquiridas por ciências diversas. Não obstante, essas ciências continuariam dizendo respeito à mesma coisa, como é o caso da música e a aritmética. A música, que ele também definiu por ciência das consonâncias, ou harmônica, participava por vezes do mesmo nome que a ciência subalternante, dado que o sujeito da subalternante, por meio de uma condição acrescentada, torna-se o sujeito da subalternada (NASCIMENTO, 2009, p.225).

Para Grosseteste, o número relacionado estava classificado abaixo do número aritmético (numerus simpliciter), mas não era substancialmente idêntico a este, nem a ele reduzível, de sorte que o aritmético conseguiria somente tirar conclusôes universais sobre a música, independentemente da determinação física (ad aliquid) que se encontrava sob o conhecimento particular do músico.

Grosseteste desenvolveu essa afirmação, sintetizando Boécio e Aristóteles sob o "guarda-chuva" do quadrivium (HIRTLER, 1995, p.36-43). Ao comentar a subalternação em Aristóteles, que dividia harmonica secundum 
auditum da harmonica mathematica ${ }^{9}$, Grosseteste associou a primeira ao numerus relatus sonorus e a última ao numero relatus. Utilizando o composto número + relacionado, contrariamente às doutrinas pitagórico-platônicas, Grosseteste estabeleceu uma separação no nível ontológico entre número e natureza (RICO, 2005, p.160).

Enquanto Grosseteste caracterizou o numerus relatus sonorus como uma espécie de um gênero mais geral, Aquino considerou-o o próprio gênerosujeito da Música (NASCIMENTO, 2007, p.57). Segundo Nascimento, para Aquino, a relaçáo entre o gênero sujeito da disciplina matemática e o da ciência intermediária poderia ser formulada como a relação de uma forma quantitativa com a matéria sensível. Dessa maneira, Aquino garantia a unidade dos sujeitos das ciências intermediárias, que tendiam a constituir uma justaposição de partes de acordo com a ideia de Grosseteste, podendo-se sustentar que Aquino complementava uma observação de Aristóteles, não suficientemente explorada por Grosseteste (NASCIMENTO, 2007, p.57). Aquino previa que o número sonoro fosse a aplicação da forma numérica (que o aritmético estudava) a matéria, ou seja, aos sons ${ }^{10}$. Aquino, de forma semelhante, tomou, a exemplo de Aristóteles, o número como a causa formal do objeto musical somado ao físico, a matéria ${ }^{11}$.

Assume-se então a possibilidade de, nas ciências intermediárias, a ciência inferior poder aplicar o objeto matemático e os seus princípios à matéria (NASCIMENTO, 1974, p.52-54; 2007, p.56). Aquino tratou também da demonstração dessas ciências, sendo que a demonstração do porquê competiria às matemáticas e a explicação de quê, às ciências intermediárias (NASCIMENTO, 1995, p.40-51).

\section{A NoÇÁo de CIÊNCIA No SÉCUlo XVI E SEUS DeSAFIOS}

Desse modo, o caráter aritmético e subalterno da música foi transmitido à Renascença. Essa classificação da música estava de acordo com as Abaseados

\footnotetext{
${ }^{9}$ Aristóteles, em Analíticos Posteriores (I, 13, 79a5-6), divide a aritmética e a música, música matemática (harmonica) e música acústica (musica secundum auditum). Nesse sentido, uma forte dependência da música com relação à aritmética aparece, ao mesmo tempo que da música matemática com relação à música acústica.

10 "[...] musica applicat numerum formalem (quem considerat arithmeticus) ad materiam, id est ad sonos." (Expositio libri Posteriorum, I, 25, p. 91).

${ }^{11}$ Aristóteles, Física II, 3 (194b27); Metafísica V, 2 (1013a25-8). Tomas de Aquino, Commentaria in libros Physicorum, II, 5, p. 69; e In Metaphysicam Aristotelis, V, 2, p. 255.
} 
nos intervalos de oitava e quinta $)^{12}$. Contudo, a descoberta de instrumentos antigos e de manuscritos com músicas, como no caso de escritos do autor grego Alypio, que foram providos pela primeira vez na obra de Vincenzo Galilei (GALILEI, 1580, p.96-97), assim como o desenvolvimento de instrumentos modernos, com registros mais extensos e a prática de conjuntos cada vez mais heterogêneos, demandaram mudanças teóricas.

\section{3a Sistemas de afinaÇáo COMO DESAFio}

Havia, desde a publicação da obra de Ramos de Pareja (ca.1440-1522), Musica practica, de 1482, uma alternativa para o uso de razóes não pitagóricas, sobretudo na tentativa de estabilizar o uso de intervalos de terças, quintas, quartas e oitavas (ADKINS, 1963, p.189). Para tal, formas de temperar ${ }^{13}$ os intervalos apareceram, e os sistemas de intonação justa e outras formas de meio e quarto de tempero foram utilizados (ADKINS, 1963, p.188-189; BARBOUR, 2004), como os propostos nas obras do espanhol Francisco Salinas (1513-1590) (SALINAS, 1577) e do italiano Gioseffo Zarlino (1571), nas quais terças e oitavas eram mantidas justas, enquanto quintas, quartas e terças menores ficavam impuras (COHEN, 1987, p.476).

Outro sistema em voga era o chamado tempero igual, mas que estava relacionado a uma proibição. Esse sistema apareceu em instrumentos de corda com traste como o alaúde. Vincenzo Galilei havia defendido e explicado o seu uso em alguns de seus tratados (GALILEI, 1568; 1580; 1584; BARBOUR, 2004, p.8).

\section{3в O TEMPERO IGUAL COMO UM CASO ESPECIAL}

Teoricamente, o tempero igual requeria a divisão do tom $^{14} \mathrm{em}$ duas partes iguais. Sabe-se que, historicamente, os pitagóricos haviam tentado dividir intervalos musicais em subintervalos iguais, ou seja, eles tentaram

\footnotetext{
${ }^{12}$ Intervalo é a designação dada à distância que existe entre dois sons, como do1-do2 (oitava), ou dosol (quinta).

${ }^{13}$ Temperamento, derivado do latim temperamentum, deve ser compreendido como uma forma de misturar coisas na mesma proporção. No caso da música, redistribuir proporcionalmente, a cada nota, o necessário para a sua igualdade como grupo.

${ }^{14}$ Vale lembrar que, nessa época, tom e semitom, que atualmente equivalem respectivamente à soma de dois semitons e à menor quantidade de som utilizada na música, possuíam diversos "tamanhos". $\mathrm{O}$ tom poderia ser maior ou menor, assim como o semitom, sendo representados por razōes diferentes.
} 
encontrar uma média geométrica desses intervalos, chegando à conclusão de que, da forma tradicional aritmética, não era possível. Evidência textual foi a proposição 3 do Sectio canonis (SZABÓ, 1978, p.174-177). De acordo com a regra, os intervalos epimóricos ou superparticulares ${ }^{15}$ não poderiam ser divididos em partes iguais. Na prática, a divisão do tom em duas partes iguais só poderia ser alcançada de maneira mecânica, ou seja, através do uso de instrumentos como o mesolábio, que inserissem médias proporcionais ${ }^{16}$.

Galilei havia sido o responsável pela divulgação da obra do filósofo e matemático grego Aristoxeno de Tarento (PALISCA, 1994, p.189-199), em cujo Elementa harmonica $(2.46,56-57)$ se admitiu teoricamente a divisão do tom em duas partes iguais. Matematicamente, a proposta de divisão do tom em duas partes iguais era conhecida desde a publicação do trabalho de Nicola de Cusa, em 1450 (ABDOUNUR, 2001). O matemático Faber Stapulensis (1455-1537) havia proposto, no seu trabalho de 1494, uma construçáo geométrica da divisão geométrica de Cusa (ABDOUNUR, 2011). Teóricos do século XVI, como Juan Bermudo, Piero Ciruelo, além de Galilei, Salinas e Ganassi ${ }^{17}$, experimentaram também na prática essa divisão. A solução mecânica, principalmente a oferecida pelo instrumento chamado mesolábio, era conhecida através de autores como Vitrúvio, Eutóquio Ascalonita, Eratostene di Cirene (séc. III a.C.), em cujos textos se proviam explicaçóes de seu funcionamento. Obras como o livro quatro da Geometria de Giorgio Valla mencionaram a finalidade do objeto, sem maiores detalhamentos sobre seu funcionamento (BARBIERI, 1993, p.202-203).

Não obstante a evidência textual que explicava e legitimava o uso, Zarlino recorreu à proibição da divisão do intervalo musical em duas partes iguais, baseando-se textualmente nas obras Arithmetica, de Girolamo Cardano, e Arithmetica, de Boécio (ZARLINO, 1558, p.47-48).

Zarlino, apesar de ser mestre-capela, era um músico teórico, cuja prática musical era restrita. No seu capítulo sobre o que é a Música, da obra Istitutione, ele afirmou o caráter especulativo matemático da música, explicando que, para a sua devida compreensão, a qual se dava em nível intelectual, não era necessário o conhecimento prático, quer através de instrumentos, quer da voz

\footnotetext{
${ }^{15}$ Os intervalos epimóricos ou superparticulares são do tipo “( $\left.n+1\right): n$ ”, que exemplificam os intervalos mais caros aos pitagóricos que eram as quartas, as quintas e as oitavas.

${ }^{16}$ Essa proibiçáo já era conhecida desde o Sectio canonis, prop.3, como era também citada por todos os autores, desde Boécio até o século XVI.

${ }_{17}$ GANASSI, S. Lettione seconda pur della prattica di sonare il violone d'arco da tasti. 1543. Bologna: Forni, 1970.
} 
(ZARLINO, 1558, p.20). Com relação ao tempero propriamente dito, ele enfatizou:

Este tal temperamento, que os modernos chamam de participação, e que eu náo sei, se até hoje existiu alguém que tivesse pensado sobre isso, [...] acredito verdadeiramente [que tal temperamento] tenha sido introduzido ao acaso e não através de estudos. (ZARLINO, 1558, p.125, tradução nossa).

Contudo, na mesma obra em que desmereceu o temperamento, Zarlino citou as demonstraçôes matemáticas da divisão do tom em partes iguais de Michael Stiefel ${ }^{18}$ e Nicolò Tartaglia ${ }^{19}$, para considerá-las inúteis (ZARLINO, 1571, p.159).

Zarlino, emprestando os conceitos de Aristóteles, argumentou que o verdadeiro conhecimento de algo se daria somente com o conhecimento de seus primeiros princípios (ZARLINO, 1558, p.2). Zarlino estabeleceu, na Istitutione, três primeiros princípios e o objeto da música, que foram, respectivamente: a oitava, como o intervalo musical capaz de gerar os demais (ZARLINO, 1558, p.142, p.149), o senario, como o grupo de intervalos escolhidos, ou seja, o grupo de consonâncias possíveis (ZARLINO, 1558, p.25-26) e a ordem natural, ou lugar dos intervalos (ZARLINO, 1558, p.52); e, finalmente, o objeto da música, o número sonoro (ZARLINO, 1558, p.28-30).

Essa obra de 1558, que teve sua edição reformulada em 1573 e uma versão final em 1589 (CORWIN, 2008, p.13), foi sendo revisada em seu conteúdo. A segunda obra do autor, Dimostratione, foi publicada em 1571, ou seja, antes da segunda versão da Istitutione. Todavia, na edição de 1558 já apareciam mençóes do autor à obra Dimostratione (ZARLINO, 1558, p.141) ${ }^{20}$. $\mathrm{Na}$ Dimostratione, Zarlino recorreu às maneiras de demonstração das ciências para comprovar a veracidade e superioridade do sistema que propunha.

$\mathrm{O}$ autor iniciou o primeiro ragionamento da Dimostratione com uma discussão sobre "[...] como os grandes autores gregos concordavam no caráter

\footnotetext{
${ }^{18}$ STIEFEL, M. Arithmetica integra, livro I, cap.9.

${ }^{19}$ TARTAGLIA, N. General trattato de’ numeri et misure [...]. Venezia: Curzio Troiano, 1556, parte II, $115-118 \mathrm{v}$.

${ }^{20}$ Historiograficamente, esse fato passa despercebido, sendo Keheller talvez um dos poucos autores a mencioná-lo. Um estudo da relaçâo entre as obras de Zarlino e Galilei seria de extrema importância para elucidar as discussōes conceituais de ambos. Tal estudo ainda não foi feito, mas não cabe aqui elencar os tópicos que poderiam ser desenvolvidos.
} 
dissonante dos intervalos menores de quarta”. Zarlino, através das personagens do texto, explicou que os antigos quiseram ouvir os intervalos menores do que a quarta e que o fizeram de duas maneiras.

$\mathrm{Na}$ primeira, sob as formas contidas na divisão em sete espaços da oitava, e depois, sob outras formas (ZARLINO, 1571, p.3). Com relação às outras formas, havia uma maneira na qual ouviam sons dissonantes, visto que as formas restavam no gênero superpartiente ${ }^{21}$. Na segunda maneira, a qual ele também subdividiu, os sons poderiam ser consonantes. De acordo com essa subdivisão, na primeira, seriam consonantes por estarem nos seus verdadeiros lugares naturais, mas não poderiam ser ouvidos, uma vez que os instrumentos não os comportariam. $\mathrm{Na}$ segunda, estariam fora de seus lugares naturais, o que implicaria dissonância. Em nenhuma das maneiras elencadas o autor descreveu o procedimento de colocação dos intervalos.

Esse primeiro ragionamento resumiu mais uma vez os preceitos apresentados na Istitutione. Conforme o autor, existia uma relação dos intervalos com razóes específicas, e aqueles que se encontravam fora delas eram dissonantes; o segundo exemplo salientou que, por vezes, mesmo que as razões de intervalos fossem legítimas, poderia não existir instrumento que os comportasse, e, por último, asseverou que o lugar inapropriado de um intervalo o tornava dissonante.

Para passar para as demonstraçóes práticas, que caracterizavam os últimos ragionamenti, ele distinguiu entre o que seria a definição e a descrição. Segundo Zarlino, a definição era o que explicava a coisa de acordo com suas essências, e a descrição, o que as explicava por seus acidentes, repetindo a definição do número sonoro.

Essa recorrência ao objeto foi feita para possibilitar a modificação da sua definição de consonância e deixá-la de acordo com os tipos de causas aristotélicas. Aristóteles ressaltava que a razão numérica era a causa formal da consonância (Física, I, 3, $194 \mathrm{~b} 27$ e Metafísica V, 2, 1013a25-28). De acordo com Zarlino, consonância era razão de número, contida entre dois sons, um grave e outro agudo, sendo a causa formal a razão numérica, a causa material, o som, e a causa final, a consonância (ZARLINO, 1571, p.10). Para Galilei e

${ }^{21}$ Superpartiente: relação na qual um número maior possui totalmente o menor mais uma, duas, três ou mais partes deste, como 5 comparado ao 3, que contém o 3 mais duas partes dele. Segundo Boécio, a classe superpartiente afastou-se de algum modo da simplicidade, pois excede-a segundo um determinado número de partes (CASTANHEIRA, 2009, p.78). 
Boécio, as consonâncias não eram definidas com relação à razão ${ }^{22}$ (GALILEI, 1570, p.25; CASTANHEIRA, 2009, p.81-82). Para Galilei, a consonância, que Zarlino abordava de acordo com as quatro causas aristotélicas, resumia-se a um fator de ordem natural. A consonância era natural, visto que pertenciam à natureza a sua matéria e comportamento. Ela possuía na matemática a sua representação; assim, concluía que as razões não eram a causa das consonâncias (GALILEI, 1589, p.21, p.79-81; PALISCA, 1989, p.152-191).

A justificativa de Zarlino para o senario, dado que era um conjunto limitado de intervalos, foi apresentada no capítulo 14 da obra de 1558, através de analogias com exemplos da existência do número seis na natureza, ou seja, do número perfeito 6 com os seis círculos que cortavam o planeta (Ártico, Antártico etc.), seis espécies de movimento etc. Zarlino explicou que o músico, assim como o aritmético, que se valia apenas dos números necessários (BOWER, 1989, p.11) ${ }^{23}$, utilizava também apenas determinados sons, aqueles definidos de acordo com o senario e não a infinidade de sons existentes.

Tendo delimitado o conjunto de intervalos possíveis, Zarlino introduziu os corpos sonoros, porque, segundo ele, náo poderia haver uma ciência "dos intervalos" que não tratasse igualmente dos corpos sonoros. Essa ciência se dava

[...] através da medida destes corpos, ou de dois corpos sonoros, ou mais precisamente de um dividido em várias partes. E se faz necessário que entre elas exista certa proporção, que seja comparada à quantidade de corda [...] e assim poderemos demonstrar com diversos meios todas àquelas coisas que são demonstráveis na Música. (ZARLINO, 1571, p.10, tradução nossa).

Segundo Zarlino, o número sonoro se encontrava "artificialmente" (artificiosamente) no corpo sonoro, mas não em qualquer corpo sonoro (ZARLINO, 1558, p.29). Ele só estaria naqueles corpos capazes de gerar consonâncias, porque esses corpos eram proporcionais a dadas formas, ou seja, à razão dos números harmônicos (ZARLINO, 1558, p.30). Apesar de Zarlino explicar que os corpos sonoros, por ele considerados, fossem quaisquer corpos capazes de uma divisão de proporção harmônica, percebe-se que a descrição na

\footnotetext{
22 "[...] consonanza non è altro che mistura di suono grave et acuto, che proviene alle nostre orechie soave et uniformemente" e Boécio, "[...] consonantia est acuti soni gravsique mixtura suaviter uniformiterque auribus accidens", ou "[...] consonância é a mistura de um som agudo e outro grave, que chega aos ouvidos de forma suave e uniforme" (CASTANHEIRA, 2009, p.81-82).

${ }^{23}$ A formulação é citada por Zarlino como sendo de Boécio, porém, encontra-se primordialmente em Nicômaco, na obra Enchiridion I, p.4.
} 
citação acima mencionada é de um monocórdio (ADKINS, 1933, p.18-34), mantendo-se preso o autor à divisão da corda.

Feita a correlação com os corpos sonoros, o autor passou à colocação dos intervalos em seus locais naturais. Como vimos, o senario estabelecia quais seriam as proporçôes que poderiam ser empregadas para representar consonâncias. A ordem dessas consonâncias no instrumento seguiria a ordem dos termos da proporção numérica. Por exemplo, a representação da proporção do intervalo de quinta, mediado pelo de terça maior e terça menor, poderia ser 15:12:10. Tomando-se o número 15 como o comprimento total da corda, terse-ia o som mais grave. A terça maior, 15:12 (5:4), representada pelos termos numéricos maiores, viria depois, e, por último, a terça menor 12:10 (6:5), realizando a ordem natural prevista pela teoria (KEHELLER, 1993, p.184). Zarlino defendia que somente nesse tipo de proporção os lugares naturais estariam validados.

Tal ordem ainda corroborava um de seus primeiros princípios, o da oitava, como sendo o intervalo que gerava os demais. Zarlino evocava, para tal, a noção de primum de Marcilio Ficino (ZARLINO, 1558, p.142) e colocavase contrário àqueles que consideravam a diesis, a menor parte com a qual se formavam intervalos maiores ${ }^{24}$.

A esse construto de Zarlino, Galilei, reconhecido como um exdiscípulo, foi se opondo ${ }^{25}$. Galilei, um músico teórico e prático, tocava o alaúde e utilizava o tempero, que era um sistema diferente do usado por Zarlino. Galilei havia publicado, em 1568, a obra Il Fronimo, na qual explicou a colocação desses intervalos no alaúde (GALILEI, 1568; 1584). Conforme mencionado, Zarlino demonstrou desconhecer o tempero e não fez jamais menção ao Il Fronimo.

Galilei apresentou, no seu tratado de 1570, uma maior sistematização de definições ${ }^{26}$, que expunham a música como ciência, seu sujeito, as definiçóes de números, razóes e suas espécies (GALILEI, 1570, p.2-16).

\footnotetext{
${ }^{24}$ Aristóteles, Meta. X, 2, 1053b9-1054a18.

${ }^{25} \mathrm{~A}$ única comprovação documental de que Galilei teria estudado com Zarlino indica que teria sido por um breve período, durante o ano de 1562. Ver BROMBERG (2011).

${ }^{26}$ Esse tratado, que permanece em forma manuscrita, foi pouco estudado e é raramente citado na literatura. Cf. Compendio di Vincentio Galilei della Teorica della Musica (c.1570) (Biblioteca Nazionale Centrale di Firenze, Anteriori di Galileo. Vol.4, 3r-47v). Ver MOYER (1992).
} 
Nessa lista, Galilei, por vezes, repetiu definiçôes dadas por Zarlino, em sua Institutione, mas, por outras, se distanciou, todavia sem criticar abertamente a abordagem de Zarlino. Nessa obra, ele classificou a música como sendo subordinada à geometria, por emprestar desta a magnitude, e à aritmética, por emprestar desta o número (GALILEI, 1570, p.8). Ele também considerou o objeto da música o número sonoro, explicando que era sonoro quanto à matéria, e número, quanto à forma (GALILEI, 1570, p.9).

A subalternação da música defendida por Galilei não encontrava lugar no sistema zarliniano. As explicaçóes que Zarlino dava sobre a participação da geometria e da superior hierarquia da aritmética constituíam-se, como salientava Galilei, numa forma incompleta, visto que a matemática não conseguia abarcar a totalidade das características musicais. $\mathrm{O}$ distanciamento que Galilei foi tomando dos preceitos de Zarlino ficou claro, na sua próxima obra publicada, o Dialogo de 1580 , na qual o autor criticou abertamente Zarlino e mencionou que outras obras suas teriam sido boicotadas, muito provavelmente em razão das discordâncias ${ }^{27}$. No Dialogo, um dos principais objetivos de Galilei foi mostrar a falácia do sistema teórico de Zarlino.

Após uma breve introdução, Galilei evidenciava como o sistema sintônico adotado por Zarlino gerava, na prática - e ao contrário do que propunha a teoria -, intervalos dissonantes. Galilei apresentou o quadro teórico dos intervalos e suas razóes como proposto por Zarlino (GALILEI, 1580, p.3). Um a um, ele foi construindo os intervalos e discutindo a possibilidade de seus tamanhos, suas colocaçóes e subsequentes resultantes sonoros. Por exemplo, ao aludir ao intervalo de quinta, Galilei a definiu como composta por uma quarta (4:3) mais um tom menor (10:9), um intervalo racionalmente possível no sistema de Zarlino. Contudo, o resultado 40:27 produzia um intervalo dissonante (GALILEI, 1580, p.3-25).

A demonstração matemática dos intervalos mostrava que a causa final não estava de acordo com a formal. Galilei partiu ainda da consonância para

\footnotetext{
${ }^{27}$ Entre a publicação do Compendio e a segunda obra teórica do autor, o Dialogo de 1581, há um período de tempo razoável, no qual náo aparecem publicações de Galilei. A esse período Galilei se refere na obra Discorso, atestando que outros escritos seus teriam sido entregues a Zarlino, mas boicotados (GALILEI, 1589, 17). A partir da década de 1580, os autores direcionarão suas obras e seus ataques um ao outro, num debate que durará até a morte de ambos, na década de 1590 . Palisca atribui a mudança de postura de Galilei ao seu contacto com o filólogo romano Girolamo Mei, o qual o teria iniciado na teoria musical da antiguidade e lhe fornecido os dados com os quais questionou Zarlino. De acordo com Palisca, Galilei teria mantido uma correspondência com Mei que perdurou por dez anos, porém, desse epistolário sobreviveram apenas seis cartas. Ver PALISCA (1977-1989).
} 
a sua representação, indicando que intervalos, que sonoramente se provavam consonantes, podiam ser representados por razóes que o senario náo abarcava, revelando a distância que existia entre o sistema teórico defendido por Zarlino e a sua execução ${ }^{28}$.

Para Galilei, a axiomatização dos primeiros princípios provia nada mais do que a descrição dos próprios objetos e, quando houve demonstraçóes, as quais deveriam tornar esses objetos perceptíveis ao sentido, como prometia Zarlino, os resultados provaram ser diferentes daqueles propostos no procedimento axiomático. Entretanto, Zarlino recusava-se a admitir: "Vê-se a grandeza da demonstração, a qual, confirmada pelos princípios, faz com que saibamos verdadeiramente as coisas, sendo que é impossível que as coisas se deem de maneira diversa daquela demonstrada" (ZARLINO, 1571, p.36, tradução nossa).

Como Galilei demonstrava, na investigaçâo dos corpos sonoros, existiam mais do que os elementos matemáticos (GALILEI, 1580; 1589; 1590). Segundo ele, Zarlino náo se preocupava com a verdade da natureza do fenômeno, mas reduzia as variáveis existentes no estudo do corpo sonoro ao seu sistema. Ao fazer isso, Zarlino tomava por certo duas errôneas conclusões, de que entes geométricos podiam ser tratados por princípios aritméticos e de que corpos sonoros fossem resumidos a características de entes geométricos.

Zarlino, invertendo a argumentação, tentava desmerecer as demonstraçôes de Galilei, alegando que, em essência, todo o seu conhecimento provinha da prática musical. Galilei prontamente respondeu que, em primeiro lugar, era ele, Zarlino, que procedendo a partir de seus primeiros princípios, tinha-os como verdadeiros e evidentes por si só, e que em suas demonstrações assumia o desconhecido e provava aquilo que já era sabido, e que, em segundo lugar, ele, Galilei, partia de demonstraçóes matemáticas e não do experimento com instrumentos, como sustentava Zarlino e como poderia ser comprovado por qualquer um que lesse os seus tratados (GALILEI, 1590?, p.46-47).

Galilei insistiu em que as demonstraçôes não deveriam partir dos primeiros princípios eleitos por Zarlino (GALILEI,1590?, p.54). Seriam três os elementos na demonstração: o que se demonstra, a saber, a conclusão um atributo que é inseparável de um gênero -, os axiomas ou premissas das

${ }^{28}$ Galilei traz a sua comprovação através da descrição de diferentes instrumentos, explicitando como as diversas mecânicas, formatos e materiais influenciam na produção sonora, fazendo com que mesmo intervalos apresentem diferentes razóes de proporçôes (GALILEI, 1580, p.98-100; 1589-90 apud PALISCA, 1989, p.152-191). 
demonstraçóes e o gênero sujeito, cujos atributos essenciais são revelados pela demonstração, em acordo com os preceitos de Aristóteles (Seg. An. I 7, 75b).

Galilei criticou as demonstraçóes dadas sobre o instrumento helicon, na proposição II, 14 da Dimostratione, na qual Zarlino mostrou as relaçóes proporcionais entre os segmentos do helicon, ao invés de demonstrar as relaçóes proporcionais que resultavam de triângulos semelhantes e da divisão das figuras. Galilei ofereceu, em seu Discorso, uma demonstração substitutiva à de Zarlino (GALILEI, 1589, p.55-56). Para Galilei, a construção geométrica era a base da qual se iniciava a demonstração com o helicon. A demonstração servia para provar a proporcionalidade entre as figuras semelhantes. Segundo ele, Zarlino ignorava as figuras tomadas na demonstração, porque se preocupava somente com os segmentos das figuras que revelavam as razóes do senario. Vale lembrar, como sabia Galilei, que a demonstração original fornecida por Ptolomeu (Harmonics, livro III) possuía uma aplicação direta na divisão de cordas, fator também ignorado na demonstração de Zarlino (BARKER, 2007).

Galilei mantinha seus argumentos, atestando que partia tanto de suas demonstraçóes matemáticas quanto da natural (GALILEI, 1590?, p.44-47), e que não havia nada de arbitrário em suas demonstraçóes. Zarlino, para inserir o mundo natural em suas demonstraçóes, passou então, na obra Sopplimenti, para a sua última definição de consonância, adicionando a esta o termo "natural" (ZARLINO, 1589, I, 4, p.19).

O Sopplimenti foi uma obra construída por tópicos, que eram nada mais do que cópias de trechos de obras de Galilei apontadas como "erros de outros". Ao abordar o segundo erro, Zarlino descreveu como "outros" tentaram demonstrar racionalmente e não mais "demonstrativamente" coisas da música. Segundo Zarlino, o seu método proveria o único meio de se atingir o verdadeiro conhecimento e que, apesar "de outros" terem demonstrado diferentemente, ele continuaria se servindo de seus próprios escritos (ZARLINO, 1571, p.38). Na mesma justificativa, Zarlino recorreu à Metafísica de Aristóteles, completando que bem dizia o filósofo que as disciplinas matemáticas tinham o primeiro grau de certeza seguida pela natural (ZARLINO, 1571, p.37), já que, embora a música pudesse estar entre a matemática e a natural, seria definida pela primeira por ser esta a mais nobre.

Galilei, que não via na aritmética uma ciência superior, defendia que, para se obter o conhecimento dos princípios e das conclusóes de uma ciência, seria necessário estar de posse de ambas as ciências. Em seu Discorso de 1589, 
trouxe exemplos, explicando que o teórico, embora soubesse a razão matemática do intervalo, não sabia reconhecê-lo auditivamente, enquanto o músico conhecia o intervalo, sem saber sua razão (GALILEI, 1589, p.29). No Dialogo, ele explicou que o músico seria aquele que possuísse os conhecimentos teórico e prático, criticando abertamente os músicos que se restringiam ao conhecimento da prática musical (GALILEI, 1581), e os teóricos que desconheciam a prática. Os exemplos foram dados para ilustrar "[...] quantos inconvenientes ocorrem quando aqueles que tratam das ciências e artes não conhecem os seus princípios" (GALILEI, 1589, p.40). Zarlino retrucou, classificando os princípios, aos quais se referia Galilei, como elementos, visto que poderiam ter forma e matéria (ZARLINO, 1588, II, 3, p.48). Sempre na tentativa de restabelecer o caráter especulativo da música e da não participação da matéria, num objeto caracterizadamente matemático, Zarlino partiu, em seu Sopplimenti, para uma síntese da categorização das coisas como fornecida por Aquino e concluiu, mais uma vez, que a música era uma ciência quadrivial subordinada à aritmética, cujo objeto era imutável (GOLDBERG, 2011, p.115).

A natural, segundo Zarlino, somente forneceria demonstraçóes quia, por tratar dos efeitos. Segundo ele, os exemplos com instrumentos tratados por Galilei proviam um estudo do particular, criando uma experiência singular da qual não se poderia conhecer nem aplicar nada (ZARLINO, 1588, I, p.25). Válidos seriam os universais (ZARLINO, 1588, I, cap.7).

Galilei parecia aproximar-se de uma ideia de subalternação $0^{29}$, a qual pudesse considerar que as mesmas proposiçôes podiam servir de princípio ou de fim, dependendo do ponto de vista abordado, como vimos nos exemplos e críticas a Zarlino.

\section{Conclusão}

Embora o século XVI seja sabidamente reconhecido por debates que envolvem a relaçáo da matemática e da filosofia natural, como atesta a obra de

\footnotetext{
${ }^{29}$ Para Guilherme de Ockham, a relação de subalternação das ciências intermediárias estava interligada com o tipo de diversidade das conclusóes (RIBEIRO, 2004, p.58). Vale ressaltar que não se acredita que Galilei fosse um nominalista. Galilei não se afasta do fenômeno concreto (res naturales) para a sua representaçấo na linguagem, na qual a ciência é vista como investigadora da lógica das proposiçôes. Contudo, ele opta, de fato, pela investigaçáo do particular, e concorda com o nominalismo no sentido em que ataca a barreira entre percepção e realidade, provendo espaço para a natureza e o mundo real, e não para os universais, tornando os particulares formas legítimas de conhecimento.
} 
Nicolò Tartaglia, entre outros, na historiografia tradicional sobre o período, são raros os estudos que focalizam esses debates, nos tratados teóricos musicais.

A relevância da subalternação das ciências fica clara, visto que, como mostrado, aos problemas musicais existiam soluçôes matemáticas, tanto textuais como práticas. A adoção ou não dessas soluçóes não estava vinculada à acessibilidade a elas, mas ao fato de elas poderem pertencer à noção de ciência adotada pelo teórico, que legitimava e norteava o sistema escolhido, como demonstrou a análise das obras.

A historiografia que aborda esses dois autores (Palisca, Walker, Drake, Coelho, Cohen, entre outros), surpreendentemente, ignora não só as suas demonstraçôes matemáticas, mas também suas arguições sobre a classificação das ciências.

BROMBERG, Carla. The Objects of Music and Mathematics and the Subordination of Sciences in Musical Treatises of the 16th century. Trans/Form/Ação, Marília, v. 37, n. 1, p. 9-30, Jan./Abril, 2014.

\begin{abstract}
It is assumed that during specific periods in history Music and Mathematics were fields which had shared concepts and topics of discussion. A very well known period in which such a communion was specific prolific was the Renaissance. Music was then a mathematic science classified within the quadrivium. During the Renaissance, this conception was well known through the works of the philosopher Boethius and the notion of the subalternate sciences was disseminated through the works of Aristotle and his commentators. However, in the sixteenth century, reformulations were demanded by a number of authors. In the works of Gioseffo Zarlino (1517-1590) and Vincenzo Galilei (1533?-1591) the question on the classification of Music and Mathematics was specifically relevant in challenging the theoretic framework. Therefore, the aim of this article is to demonstrate the relevant role of the discussion on the subalternation of sciences, as it is known that one of the central methodological problems in the demonstration of sciences during the sixteenth century was the definition and reconciliation of the abstract mathematic object and the natural object.
\end{abstract}

KEYWORDS: History of Science. Subalternation of Sciences. Knowledge Classification. Music and Mathematics. Renaissance. 


\section{REFERÊNCIAS}

ABDOUNUR, Oscar João. Ratios and Music in the Late Middle Ages: a preliminary survey. [Berlin]: Max-Planck Institute for the History of Science, 2001, p.22-69 (Preprint 181).

. Geometry and theoretical music in the Renaissance. In: SEROUGLU, Fanny; KOULOUNTZOS, Vassilis; SIATRAS, Anastasius (Ed.). Science \& culture: promise, challenge and demand. Athens: Epikentro, 2011, p. 16-19.

ADKINS, Cecil. The Theory and practice of the Monochord. 1963, 501f. Tese (Doutorado em Filosofia) - State University of Iowa, City of Iowa, 1963.

AQUINO, Tomás de. Comentário ao Tratado da Trindade de Boécio: questóes 5 e 6. Tradução e introdução de Carlos Arthur R. do Nascimento. São Paulo: Fundação Editora da UNESP, 1999.

. Expositio libri Posteriorum, ed. Leonina, Opera omnia 1/2. Roma: xxx, 1989.

. In Metaphysicam Aristotelis, ed. M. Cathala. Turin: Marietti, 1935.

. Commentaria in libros Physicorum, ed. Leonina, Opera omnia 2. Roma: Typographia Polyglotta, 1884 .

ARISTÓTELES, Metafisica. Tradução, textos adicionais e nota de Edson Bini. Bauru, SP: EDIPRO, 2006.

ARTUSI, Giovanni. M. L'Artusi, ouero delle imperfettioni della moderna musica ragionamenti dui. Venice: Giacomo Vincenti, 1600.

. L'Arte del contrapunto. Venentia: Giacomo Vincenti, 1598.

BARBERA, Andre. The Euclidean Division of the Canon: Greek and Latin Sources. Lincoln and London: University of Nebraska Press, 1991.

. The persistence of Pythagorean mathematics in ancient musical thought. Chapel Hill: University of North Carolina at Chapel Hill; University Microfilms International, 1980.

BARBIERI, Patrizi. Il mesolábio e il Compasso di Proporzione: le applicazioni Musicali di due Strumenti matematici (1558-1675). In: PASADORE, F.; ROSSI, F. Musica, Scienza e Idee nella Serenissima durante il Seicento. Venezia: Fondazione Levi, 1996, p.201-220.

BARBOUR, James M. Tuning and Temperament: A Historical Survey. East Lansing, Michigan State Press, 1951. Repr. New York: Dover, 2004.

p.286-304, 1933.

BARKER, Andrew. The Science of Harmonics in Classical Greece. Cambridge: Cambridge University Press, 2007.

. Greek Musical Writings. vol. 2. Cambridge: Cambridge University Press, 1989.

BOWER, Calvin. Boethius. Fundamentlas of Music (trans) Calvin M. Bower. New Haven \& London: Yale University Press, 1989. 
Boethius and Nicomachus: An Essay Concerning the Sources of De institutione musica. Vivarium, vol. 16, 1, p. 1-45, 1978.

BROMBERG, Carla. Vincenzo Galilei contra o número sonoro. São Paulo: FAPESP -EDUC/ Livraria da Física, 2011.

CASTANHEIRA, Carolina. P. De istitutione musica, de Boécio- livro I: Tradução e comentários, 2009. 158p. Dissertação (Mestrado em Filosofia) - Universidade Federal de Minas Gerais, Belo Horizonte, 2009.

COHEN, Floris. Quantifying music: The Science of Music at the First Stage of the Scientific Revolution 1580-1650. Dordrecht: D. Reidel, 1993.

1987.

. Simon Stevin's Equal division of the Octave. Annals of Science, vol.44, p.471-488,

CORWIN, Lucille. Le istitutione Harmoniche of Gioseffo Zarlino, part I: A Translation with Introduction. 2008.547p. Tese (Doutorado em Filosofia) - The City University of New York, New York, 2008.

DANTE, Egnazio. Le Scienze matematiche ridotte in tavole. Bologna: Compagnia della Stampa, 1577.

FOGLIANO, Ludovico. Ludovici Foliani Mutinensis de musica theorica. Venice: Io. Antonius et Fratres de Sabio, 1529.

GAFFURIO, Franchino. The Theory of Music. (trans.) with introduction and notes by Walter K.Kreyszig, New Haven/London: Yale University Press, 1993.

GALILEI, Vincenzo. Il primo libro della prattica del contrapunto intorno all'uso delle consonanze (1588-91); Discorso particolare intorno alla diversità delle forme del diapason (s/d); Discorso intorno all'uso delle dissonanze (1588-91); Discorso intorno all'uso dell'enharmonio et di chi fusse autore del cromatico, (1590-91); Dubbi intorno a quanto io ho detto dell'uso dell'enharmonico, con la solutione di essi (1591). In: REMPP, F. Die Kontrapunkttraktate Vincenzo Galileis, Vol.9. Cologne: Arno Volk, 1980 (Veröffentlichungen des Staatlichen Instituts für Musikforschung).

. Discorso intorno a diversi pareri che hebbono le tre sette piu famose degl'antichi musici, intorno alla cosa de suoni, et degli acchordi(s/d); Discorso particolare intorno all' unísono(s/d); Discorso particolare intorno alle diversità delle forme del diapason. In: PALISCA, Claude. The Florentine Camerata: Documentary Studies and Translations. New Haven: Yale University Press, 1989, p.152-207. (Music Theory Translation Series).

. Dialogo di Vincentio Galilei nobile fiorentino della musica antica et della moderna. Florence: Filippo Giunti, 1580/1602.

. Critica fatta di Vincentio Galilei intorno ai supplementi musicali di Gioseffo Zarlino. Biblioteca Nazionale Centrale di Firenze, Anteriori di Galileo, 1590? (Vol.5, fol.3r-58r.)

. Discorso intorno alle opere de Gioseffo Zarlino et altri importanti particolari attenenti alla musica. Florence: Giorgio Marescotti, 1589. 
. Il primo libro di madrigali a quator et cinque voci di Vicentio Galilei nobile fiorentino. Venice: Antonio Gardano, 1574.

Compendio di Vincentio Galilei della Teorica della Musica. Biblioteca Nazionale Centrale di Firenze, Anteriori di Galileo (c.1570). Vol.4, fol.3r-47v.

. Il fronimo: dialogo... sopra l'arte del bene intavolare, et rettamente sonare la musica negli strumenti artificiali si di corde come di fiato, $\&$ in particolare nel liuto. Venice: Girolamo Scotto, 1568 (2. ed.1584/R1969).

.Intavolature di lauto di Vincenzo Galilei Fiorentino, madrigali e ricercari libro primo. Rome: Valerio Dorico, 1563.

GANASSI, Silvestro. Lettione seconda pur della prattica di sonare il violone d'arco da tasti. 1543. Bologna: Forni, 1970.

GOLDBERG, Randall. Where Nature and Art adjoin: Investigations into the ZarlinoGalilei dispute with a translation of the Discorso intorno alle opera di messer Gioseffo Zarlino. 2011. 418p. Tese (Doutorado em Filosofia) - Indiana University, Indiana, 2011.

HEATH, Thomas. A History of Greek Mathematics. 2 vols. New York: Dover, 1981.

HENTSCHEL, Frank. Sinnlichkeit und Vernunft in der mittelalterlichen Musiktheorie: Strategien der Konsonazwertung und der gegenstand der musica Sonora um 1300. Stuttgart: Franz Steiner, 2000.

HIRTLER, Eva. Die Musik als Scientia mathematica von der Spätantike bis zum Barok. Frankfurt am Main; Bern; Paris: P. Lang, 1995.

KELLEHER, John Emil. Zarlino's Dimostrationi Harmoniche and Demonstrative Methodologies in the Sixteenth Century, 1993. 405p. Tese (Doutorado em Filosofia) Columbia University, New York, 1993.

MASI, Michael. Boethian Number Theory: A Translation of the De Institutione Arithmetica.. Amsterdam: Rodopi, 1983 (Studies in Classical Antiquity, vol. 6).

MCKINLAY, Arthur. P. Stylistic Tests and the Chronology of the Works of Boethius. Harvard Studies in Classical Philology, vol.XVIII, p.123-156, 1907.

MENDOZA, Celina Lertora. El Comentario de Roberto Grosseteste al libro VII de la Física de Aristóteles. Anales del Seminario de Historia de la Filosofia, vol.21, p.71-88, 2004.

MORROW, Glenn R. Proclus: A Commentary on the First Book of Euclid's Elements. Princeton: Princeton University Press, 1992.

MOYER, Ann. Musica Scientia: Musical Scholarship in the Italian Renaissance. Ithaca/ London: Cornell University Press, 1992.

NASCIMENTO, Carlos A. Roberto Grosseteste: Física e Matemática. Comentário de Roberto Grosseteste à Física. Educação e Filosofia. Uberlândia. v. 23, n. 45, p.201-228, jan/ jun 2009.

. Tomás de Aquino e as Ciências Intermediárias. Aquinate, n. 4, p.55-65, 2007.

. De Tomás de Aquino a Galileu. Campinas: UNICAMP, 1995. 
Le statut épistémologique des sciences intermédiaires selon Saint-Thomas d'Aquin, Cahiers d'études médiévales, vol.2 p.47-65, 1974.

PALISCA, Claude V. Studies in the History of Italian Music and Music Theory. Oxford: Clarendon Press, 1994 (rep. 2001, Scientific Empiricism in Musical Thought), p. 200-235.

. Studies in the History of Italian Music and Music Theory. Oxford: Clarendon Press, 1994 (rep.2001).

. Was Galileo's Father an Experimental Scientist? In: COELHO, V. Music and science in the age of Galileo. Netherlands: Springer, 1993, p.143-52.

. The Documentary Studies and Translation: Florentine Camerata. New Haven and London: Yale University Press, 1989.

. Gioseffo Zarlino. In: The New Grove Dictionary of Music and Musicians, 20 vols. London: MacMillan, 1980.

- Girolamo Mei: Letters on Ancient and Modern Music to Vincenzo Galilei and Giovanni Bardi, Musicological Studies and Documents Vol.3, Stuttgart: Hänssler, American Institute of Musicology, 1977.

PLATÃO. A República. Introdução, tradução e notas de Mari Helena da Rocha Pereira. Lisboa: Fundação Calouste Gulbenkian, 1949.

REESE, Gustave. Music in the Renaissance. New York: W.W. Norton \& Co., 1954.

REMPP. Friedrich. Die Kontrapunkttraktate Vincenzo Galileis, veröffentlichungen des Staatlichen Instituts für Musikforschung, preussischer Kulturbesitz, Vol.9, Cologne: A.Volk, 1980.

RIBEIRO, Marcélio. A Concepção de Guilherme de Ockham sobre as Ciências Intermediárias entre a Física e a Matemática. Thesis vol. I, ano I, p.51-68, 2004.

RICO, Gilles. Music in the Arts Faculty of Paris in the Thirtheenth and Early Fourteenth Centuries. 2005. 328f. Thesis (Doctorate on Philosophy) - Oxford University, Oxford, 2005.

SALINAS, Francisco. De musica libri VII. Salamanca: Mathias Gastius, 1577.

SCHRADE, Leo. Music in the Philosophy of Boethius. The Musical Quarterly, vol.33, n.2 p.188-200, 1947.

STILLMAN, Drake. Renaissance Music and Experimental Science. Journal of the History of Ideas, vol.31, p.483-500, 1970.

SZABÓ, Árpad. The Beginnings of Greek mathematics. Dordrecht: Holland/Boston: USA: D. Reidel, 1978.

TARTAGLIA, Nicolò. Euclide... diligentemente rassettato e alla integrità ridotto per il degno Professore di tal scientie Nicólo Tartalea... Venezia: Curtio Troiano, 1565.

. General trattato di numeri et misure: la seconda parte del general trattato di numeri i misure nella quale in undci libri si notifica la piu ellevata, et speculativa parte della pratica... Vinegia: Curtio Troiano de i Navò, 1556. 
BROMBERG, C.

TEEUWEN, Mariken. Harmony and the Music of the Spheres: The Ars Musica in ninthCentury Commentaries on Martianus Capella. Leiden/Boston/Köln: Brill, 2002.

THORNDIKE, Lynn. A History of Magic and Experimental Science, vol.III. New York: Columbia University Press, 1958, p.294-324.

VOCABOLARIO DEGLI ACCADEMICI DELLA CRUSCA. Venezia: Giovanni Alberti, 1572.

WALKER, Daniel P. Studies in Musical Science in the Late Renaissance. Leiden: The Warburg Institute, University of London, E.J.Brill, 1978.

ZARLINO, Gioseffo. Sopplimenti musicali. Venice: Francesco de’ Franceschi Senese, 1588. . Dimostratione harmoniche. Venice: Francesco de’ Franceschi Senese, 1571. . Le istitutione armoniche. Venice: Francesco F. Senese, 1558.

Submissão: 06/06/2013

Aceito em: 10/09/2013 